\section{(2) \\ BRAZIULIAN JOURNAL \\ OF MEDICAL AND BIOLOGICAL RESEARCH}

www.bjournal.com.br
ISSN 0100-879X

Volume 45 (7) 565-680

July 2012

CLINICAL INVESTIGATION

Braz J Med Biol Res, July 2012, Volume 45(7) 652-655

doi: 10.1590/S0100-879X2012007500079

\title{
Evaluation of renal function in sickle cell disease patients in Brazil
}

G.B. Silva Junior, A.B. Libório, A.P.F. Vieira, A.X. Couto Bem, A.S. Lopes Filho, A.C. Figueiredo Filho, A.L.M.O. Guedes, J.H. Souza, C.M.B.E. Costa, R. Costa and E.F. Daher

The Brazilian Journal of Medical and Biological Research is partially financed by

\section{QCNPq}

da Ciência e Tecnologia

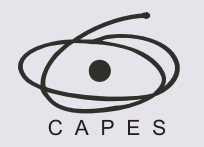

Ministério da Educação
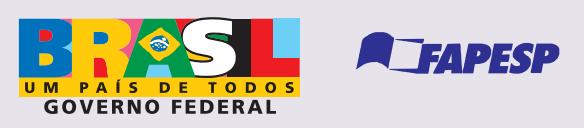

Institutional Sponsors

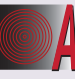

15

Associa
Fundo

Fundo
de Incentivo
apesquisa del incentivo
a Pesquisa

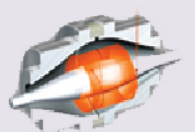

Explore High - Performance MS Orbitrap Technology andilicice Thermo

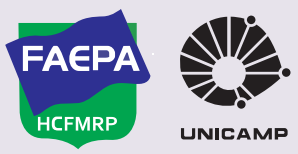

Ф SHIMADZU

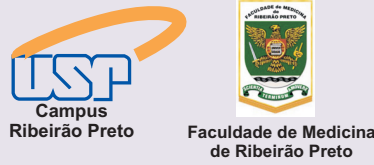

scie/o

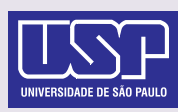




\title{
Evaluation of renal function in sickle cell disease patients in Brazil
}

\author{
G.B. Silva Junior ${ }^{1,2}$, A.B. Libório², A.P.F. Vieira1 , A.X. Couto Bem¹, A.S. Lopes Filho ${ }^{1}$, \\ A.C. Figueiredo Filho ${ }^{1}$, A.L.M.O. Guedes ${ }^{1}$, J.H. Souza ${ }^{3}$, C.M.B.E. Costa ${ }^{3}$, \\ R. Costa ${ }^{4}$ and E.F. Daher ${ }^{1}$ \\ ${ }^{1}$ Programa de Pós-Graduação em Ciências Médicas, Departamento de Medicina Clínica, \\ Faculdade de Medicina, Universidade Federal do Ceará, Fortaleza, CE, Brasil \\ ${ }^{2}$ Faculdade de Medicina, Centro de Ciências da Saúde, Universidade de Fortaleza, Fortaleza, CE, Brasil \\ ${ }^{3}$ Centro de Hematologia e Hemoterapia do Ceará, Fortaleza, CE, Brasil \\ ${ }^{4}$ Hematology/Oncology Division, Allegheny General Hospital, Pittsburgh, PA, USA
}

\begin{abstract}
The objective of this study was to investigate renal function in a cohort of 98 patients with sickle cell disease (SCD) followed up at a tertiary hospital in Brazil. Clinical and laboratory characteristics at the time of the most recent medical examination were analyzed. Renal function was evaluated by the estimation of glomerular filtration rate (GFR) by the criteria of the Chronic Kidney Disease Epidemiology Collaboration (CKD-EPI). We compared patients with normal GFR to patients with decreased GFR (<60 $\left.\mathrm{mL} \cdot \mathrm{min}^{-1} \cdot\left(1.73 \mathrm{~m}^{2}\right)^{-1}\right)$ and hyperfiltration $\left(>120 \mathrm{~mL} \cdot \mathrm{min}^{-1} \cdot\left(1.73 \mathrm{~m}^{2}\right)^{-1}\right)$. Comparison between patients according to the use of hydroxyurea and comparison of clinical and laboratory parameters according to GFR were also carried out. Average patient age was $33.8 \pm 13.3$ years (range 19-67 years), and $57(58.1 \%)$ patients were females. The comparison of patients according to GFR showed that patients with decreased GFR $\left(<60 \mathrm{~mL} \cdot \mathrm{min}^{-1} \cdot\left(1.73 \mathrm{~m}^{2}\right)^{-1}\right)$ were older, had lower levels of hematocrit, hemoglobin and platelets and higher levels of urea and creatinine. Independent risk factors for decreased GFR were advanced age $(O R=21.6, P<0.0001)$ and anemia $(O R=39.6, P<0.0001)$. Patients with glomerular hyperfiltration tended to be younger, had higher levels of hematocrit, hemoglobin and platelets and lower levels of urea and creatinine, with less frequent urinary abnormalities. Hydroxyurea, at the dosage of 500-1000 mg/day, was being administered to $28.5 \%$ of the patients, and there was no significant difference regarding renal function between the two groups. Further studies are required to establish the best therapeutic approach to renal abnormalities in SCD.
\end{abstract}

Key words: Sickle cell disease; Kidney disease; Glomerular filtration rate; Creatinine; Chronic kidney disease; Hydroxyurea

\section{Introduction}

Sickle cell disease (SCD) is the most common hereditary hematologic disease in the world and is a Public Health problem in tropical countries (1). In Brazil, the prevalence of SCD among Afro-descendants is 0.1-0.3\% (2). Renal abnormalities in SCD include microalbuminuria, proteinuria, tubular dysfunction, and glomerulopathies $(1,3)$. Patients with SCD have abnormalities in renal hemodynamics, and young patients present increased glomerular filtration rate (GFR), which seems to be associated with increased sensitivity to prostaglandins, since treatment with indomethacin significantly reduces GFR among these patients (1). The objective of this study was to investigate renal function abnormalities in SCD patients in Brazil.

\section{Patients and Methods}

A retrospective study was conducted on a cohort of 98 patients with SCD followed up at a tertiary hospital in Fortaleza city, Northeast Brazil, using a review of medical records. The study protocol was reviewed and approved by the Ethics Committee of Universidade Federal do Ceará.

Clinical and laboratory characteristics at the time of the most recent medical exams were analyzed. Renal function was evaluated by the estimation of GFR by the criteria of the Chronic Kidney Disease Epidemiology Collaboration (CKD-EPI) (4). We compared patients with normal GFR to patients with decreased GFR $\left(<60 \mathrm{~mL} \cdot \mathrm{min}^{-1} \cdot\left(1.73 \mathrm{~m}^{2}\right)^{-1}\right)$ and hyperfiltration $\left(>120 \mathrm{~mL} \cdot \mathrm{min}^{-1} \cdot\left(1.73 \mathrm{~m}^{2}\right)^{-1}\right)$. A comparison

Correspondence: E.F. Daher, Rua Vicente Linhares, 1198, 60135-270 Fortaleza, CE, Brasil. E-mail: ef.daher@uol.com.br or geraldobezerrajr@yahoo.com.br

Received November 17, 2011. Accepted April 24, 2012. Available online May 18, 2012. Published July 2, 2012. 
between patients according to the use of hydroxyurea was also done.

Data were analyzed using the SPSS version 17.0 software package. A comparison of clinical and laboratory parameters according to GFR was done. $P$ values $<0.05$ were considered to be statistically significant. The Fisher exact test and the $x^{2}$ test were used to analyze allele frequencies in the different groups. Differences between two independent variables were evaluated using the Student $t$-test or the Mann-Whitney test, as appropriate.

\section{Results}

A total of 98 patients were included. The average age was $33.8 \pm 13.3$ years (range 19-67 years), and 57 (58.1\%) patients were females. The comparison of patients according to GFR showed that patients with decreased GFR $(<60$ $\left.\mathrm{mL} \cdot \mathrm{min}^{-1} \cdot\left(1.73 \mathrm{~m}^{2}\right)^{-1}\right)$ were older, had lower levels of hematocrit, hemoglobin and platelets and higher levels of urea and creatinine, as summarized in Table 1. Urinary abnormalities (leukocyturia and proteinuria) were also more frequent among patients with decreased GFR. Independent risk factors for decreased GFR were advanced age (OR $=21.6,95 \% \mathrm{Cl}=4.0-134.6, \mathrm{P}<0.0001)$ and anemia $(\mathrm{OR}$ $=39.6,95 \% \mathrm{Cl}=5.1-417.6, \mathrm{P}<0.0001)$. A comparison of GFR according to age showed that patients older than 40 years had GFR $<60 \mathrm{~mL} / \mathrm{min}$ more frequently than younger patients (13 vs 1.5\%, P =0.03), as shown in Table 2 .

Patients with glomerular hyperfiltration tended to be younger, had higher levels of hematocrit, hemoglobin and platelets and lower levels of urea and creatinine, with less frequent urinary abnormalities compared to patients with normal and decreased GFR (Table 1). Chronic infection by hepatitis $C$ virus was detected in 6 patients $(6.1 \%)$, and by hepatitis B virus in $3(3.0 \%)$. None of these patients had decreased GFR (Table 1). Hydroxyurea, at the dosage of $500-1000 \mathrm{mg} /$ day, was being administered to 28 patients $(28.5 \%)$, with a mean time of treatment from 1 to 2 years, and there was no significant difference regarding renal function between the two groups (Table 3).

\section{Discussion}

The present study investigated the occurrence of renal
Table 2. Comparison of patients with sickle cell disease according to GFR and age.

\begin{tabular}{lcc}
\hline & $\geq 40$ years $(\mathrm{N}=31)$ & $<40$ years $(\mathrm{N}=67)$ \\
\hline GFR $<60 \mathrm{~mL} / \mathrm{min}$ & $4(13 \%)$ & $1(1.5 \%)^{*}$ \\
GFR $>120 \mathrm{~mL} / \mathrm{min}$ & $12(38.7 \%)$ & $40(59.7 \%)$ \\
Normal GFR & $15(48.3 \%)$ & $26(38.8 \%)$ \\
\hline
\end{tabular}

Data are reported as number with percent in parentheses. GFR $=$ glomerular filtration rate. ${ }^{*} \mathrm{P}<0.05$ compared to $\geq 40$ years (Fisher exact test).

function abnormalities in a cohort of patients with SCD in Brazil. SCD is associated with important renal abnormalities, including urine concentration and acidification defects, abnormal potassium excretion, proteinuria, and increased GFR (1), all potential risk factors for loss of renal function.

An increase in GFR (glomerular hyperfiltration) was detected in a high proportion of the patients studied (53\%). Previous studies found higher GFR and increased renal 
plasma flow in patients with SCD compared to controls (5). The use of equations to estimate GFR is of crucial importance for an early detection of renal function abnormalities and should be used in every patient with SCD for an early detection of glomerular hyperfiltration and to adopt measures to slow the progression of kidney disease, such as the blockade of the renin-angiotensin-aldosterone system using an angiotensin-converting enzyme inhibitor or an angiotensin II receptor antagonist (6). Recent studies have shown that the use of angiotensin-converting enzyme inhibitors in patients with SCD and proteinuria reduces urinary protein excretion (7), and this therapy could slow the progression of kidney disease.

Patients with glomerular hyperfiltration tended to be younger, had higher levels of hematocrit, hemoglobin and platelets and lower levels of urea and creatinine, with less frequent urinary abnormalities. These findings demonstrate that this is an early marker of renal dysfunction, because it occurs in the first years of the disease, and in some cases it can be detected in childhood (1). Hyperfiltration can lead to glomerulosclerosis and chronic kidney disease can then develop (8), possibly explaining the finding that advanced age was associated with decreased GFR in the present study.

Decreased GFR was associated with advanced age and anemia, which suggests that loss of renal function occurs with the progression of SCD and can be associated with uncontrolled disease, since these patients more frequently had anemia. Decreased GFR was found in $5.1 \%$ of the patients studied, and this prevalence was higher than that estimated for the Brazilian population, which is thought to have a $0.5 \%$ prevalence of chronic kidney disease among adults (9). This suggests that SCD patients have a higher risk to develop chronic kidney disease than the general population, so that measures to protect renal function should be adopted in this group of patients. Only 6 patients $(6.1 \%)$ had hepatitis $C$ virus and $3(3.0 \%)$ had $B$ virus. None of these patients had decreased GFR, so we can say that there is no association of these viruses with loss of renal function in this population. SCD is associated with an increased risk of infection. In a recent cohort of 1415 SCD patients from Salvador, Brazil, C virus infection was found in $13.4 \%$, a higher value than observed in our study, and the prevalence of $B$ virus was similar to that found by us (3.1\%) (10).

Hydroxyurea was being used by $28.5 \%$ of the patients. The use of hydroxyurea in SCD is still low and there is also poor compliance by some patients (11). Hydroxyurea could also have a beneficial impact by decreasing the chronic complications of SCD (1). In the present study, there was no difference in renal function according to the use of hydroxyurea, perhaps due to the relatively small number of patients taking this medication.

We conclude that SCD is associated with important renal function abnormalities, mainly regarding GFR. Glomerular hyperfiltration was observed in younger patients, reflecting the initial stages of renal involvement. Decreased GFR was associated with advanced age and anemia. Further studies are required to establish the best therapeutic approach to renal abnormalities in SCD. Specific treatment with an angiotensin-converting enzyme inhibitor or angiotensin II receptor antagonist should be considered in these patients in order to slow the progression of kidney disease. The role of hydroxyurea in preventing and/or treating renal function abnormalities in SCD remains to be investigated.

\section{Acknowledgments}

We are very grateful to the team of physicians, residents, medical students, and nurses from the Hospital Universitário 
Walter Cantídio, Universidade Federal do Ceará, for providing technical support for the development of this research and for the exceptional assistance provided to the patients. We acknowledge CNPq for financial support.

\section{References}

1. da Silva GB Jr, Liborio AB, Daher EF. New insights on pathophysiology, clinical manifestations, diagnosis, and treatment of sickle cell nephropathy. Ann Hematol 2011; 90: 1371-1379.

2. Naoum PC, Alvarez F, Domingos CRB, Ferrari F, Moreira HW, Sampaio Z, et al. Hemoglobinas anormais no Brasil: prevalência e distribuição geográfica. Rev Bras Patol Clin 1987; 23: 68-79.

3. Rees DC, Williams TN, Gladwin MT. Sickle-cell disease. Lancet 2010; 376: 2018-2031.

4. Levey AS, Stevens LA, Schmid CH, Zhang YL, Castro AF $\mathrm{III}$, Feldman $\mathrm{HI}$, et al. A new equation to estimate glomerular filtration rate. Ann Intern Med 2009; 150: 604-612.

5. Allon M, Lawson L, Eckman JR, Delaney V, Bourke E. Effects of nonsteroidal antiinflammatory drugs on renal function in sickle cell anemia. Kidney Int 1988; 34: 500-506.

6. Francois $\mathrm{H}$, Jacquet $\mathrm{A}$, Beaudreuil S, Seidowsky A, Hebibi $\mathrm{H}$,
Charpentier $\mathrm{B}$, et al. Emerging strategies to preserve renal function. J Nephrol 2011; 24: 133-141.

7. Fitzhugh CD, Wigfall DR, Ware RE. Enalapril and hydroxyurea therapy for children with sickle nephropathy. Pediatr Blood Cancer 2005; 45: 982-985.

8. Saborio P, Scheinman JI. Sickle cell nephropathy. J Am Soc Nephrol 1999; 10: 187-192.

9. Lugon JR. Chronic kidney disease in Brazil: a public health problem. J Bras Nefrol 2009; 31: 2-5.

10. Neto JP, Lyra IM, Reis MG, Goncalves MS. The association of infection and clinical severity in sickle cell anaemia patients. Trans R Soc Trop Med Hyg 2011; 105: 121-126.

11. Brandow AM, Panepinto JA. Hydroxyurea use in sickle cell disease: the battle with low prescription rates, poor patient compliance and fears of toxicities. Expert Rev Hematol 2010; 3: 255-260. 